\title{
Pattern electroretinogram (PERG) and pattern visual evoked potential (PVEP) in the early stages of Alzheimer's disease
}

\author{
Kamila Krasodomska • Wojciech Lubiński • \\ Andrzej Potemkowski · Krystyna Honczarenko
}

Received: 27 January 2010/ Accepted: 31 May 2010/Published online: 13 June 2010

(C) The Author(s) 2010. This article is published with open access at Springerlink.com

\begin{abstract}
Alzheimer's disease (AD) is one of the most common causes of dementia in the world. Patients with $\mathrm{AD}$ frequently complain of vision disturbances that do not manifest as changes in routine ophthalmological examination findings. The main causes of these disturbances are neuropathological changes in the visual cortex, although abnormalities in the retina and optic nerve cannot be excluded. Pattern electroretinogram (PERG) and pattern visual evoked potential (PVEP) tests are commonly used in ophthalmology to estimate bioelectrical function of the retina and optic nerve. The aim of this study was to determine whether retinal and optic nerve function, measured by PERG and PVEP tests, is changed in individuals in the early stages of $\mathrm{AD}$ with normal routine ophthalmological examination results. Standard PERG and PVEP tests were performed in 30 eyes of 30 patients with the early stages of AD. The results were compared to 30 eyes of 30 normal healthy controls. PERG and PVEP tests were recorded in
\end{abstract}

K. Krasodomska ( $)$ · W. Lubiński

Department of Ophthalmology, Pomeranian Medical

University, al. Powstańców Wlkp. 72, 70-111 Szczecin,

Poland

e-mail: kamila.krasodomska@gmail.com

\section{A. Potemkowski}

Department of Clinical Psychology, University of

Szczecin, ul. Krakowska 69, 71-004 Szczecin, Poland

K. Honczarenko

Department of Neurology, Pomeranian Medical

University, ul. Unii Lubelskiej 1, 71-344 Szczecin, Poland accordance with the International Society for Clinical Electrophysiology of Vision (ISCEV) standards. Additionally, neural conduction was measured using retinocortical time (RCT) - the difference between P100wave latency in PVEP and P50-wave implicit time in PERG. In PERG test, PVEP test, and RCT, statistically significant changes were detected. In PERG examination, increased implicit time of P50-wave $(P<0.03)$ and amplitudes reductions in P50- and N95-waves $(P<0.0001)$ were observed. In PVEP examination, increased latency of $\mathrm{P} 100$-wave $(P<0.0001)$ was found. A significant increase in RCT $(P<0.0001)$ was observed. The most prevalent features were amplitude reduction in N95-wave and increased latency of P100-wave which were seen in 56.7\% (17/30) of the AD eyes. In patients with the early stages of $\mathrm{AD}$ and normal routine ophthalmological examination results, dysfunction of the retinal ganglion cells as well as of the optic nerve is present, as detected by PERG and PVEP tests. These dysfunctions, at least partially, explain the cause of visual disturbances observed in patients with the early stages of $\mathrm{AD}$.

Keywords Alzheimer's disease · PERG - PVEP

\section{Introduction}

Alzheimer's disease (AD) is a progressive neurodegenerative disorder and one of the most common causes of dementia worldwide. It is estimated that in 
Europe alone, the number of the dementia sufferers is about $6.4 \%$ - most of them, patients with $\mathrm{AD}(4.4 \%)$ [1]. Due to the aging population, the number of patients with $\mathrm{AD}$ is on the increase and this contributes to a wider public health problem. The results of Mendez et al. [2] suggest that $43 \%$ of patients with $\mathrm{AD}$ have complex visual complaints. These patients require a proper diagnosis and suitable treatment, and the need for earlier diagnosis to slow the progression of the disease is undisputed.

Initially, $\mathrm{AD}$ symptoms are discreet and generally relate to memory deficits. However, in some cases, AD can begin with visual disturbances, including problems with reading, blurred vision, and vague complaints of poor vision. Such patients may have normal routine ophthalmological examination results including normal visual acuity and normal fundus [3-7]. The results of some studies suggest that in patients with $\mathrm{AD}$, optic nerve degeneration, and loss of retinal cells, specifically disappearance of ganglion cells and their axons is evident [8-11]. In the brain of patients with $\mathrm{AD}$, the characteristic features are beta-amyloid deposits and neurotransmitter' production disturbances, mainly decreased levels of acetylcholine. Beta-amyloid deposits were also found in the eye $[12,13]$, and acetylcholine is crucial to proper functioning of retinal cells [14].

Potential value in diagnosis of visual abnormalities in $\mathrm{AD}$ may be provided by electrophysiological studies of the retina and optic nerve such as pattern electroretinogram (PERG) and pattern visual evoked potential (PVEP) tests. These examinations measure the bioelectrical activity of retinal ganglion cells and the optic nerve. To date, the available results of PERG and PVEP tests in patients with $A D$ are inconclusive. Although abnormalities in PERG and in PVEP tests have been reported in patients with AD [15-21], normal PERG and PVEP tests results were also observed [15, 21-25].

In some PERG examinations, amplitude reduction was evident [15, 16]. Parisi et al. [17] showed a significant increase in latencies of N35-, P50-, and N95-waves and reduction in their amplitudes. Additionally, P50-wave latency increase and amplitude reduction in P50- and N95-waves were correlated with a statistically significant reduction in nerve fiber layer thickness, as measured by Optical Coherence Tomography (OCT). In PVEP examination, a latency increase in the P100-wave was observed by Pollock et al. [19], Kergoat et al. [21], and Partanen et al. [18].
The described studies were performed in patients who were at different stages of $\mathrm{AD}$, and most of them examined small numbers of patients. The aim of the current research is to evaluate retinal and optic nerve bioelectric function in patients only in the early stages of AD by means of PERG and PVEP tests.

\section{Subjects and methods}

Thirty patients in the early stages of AD (20 [66.7\%] women and 10 [33.3\%] men), aged 54-83 (mean $72.9 \pm 6.8$ ), were diagnosed in the Neurology Department of the Pomeranian Medical University in Szczecin, Poland.

Each patient with AD underwent neurologic examination including magnetic resonance imaging (MRI). All patients met the diagnostic criteria of probable AD according to the National Institute of Neurological and Communicative Disorders and Stroke and the Alzheimer's Disease Association (NINCDS-ADRDA) [26]. The inclusion criteria for the early stages of $\mathrm{AD}$ were as follows: minimal cognitive disturbances in accordance with the neurologic tests and the Mini Mental State Examination (MMSE) [27] score above 21 points. Patients were diagnosed as having AD from 6 months to 2 years. The ocular inclusion criteria were as follows: taking patient's history, visual acuity $>0.8$ (Snellen chart), normal intraocular pressure, normal kinetic visual field, no changes in anterior and posterior segment of the eye, and normal color vision. Patients with systemic disorders with known influence on the function of retina and optic nerve as well as with poor cooperation were excluded.

PERG and PVEP tests were performed in all patients (30 eyes-always left). Additionally, the measurement of retinocortical time (RCT) - a parameter described for the first time by Celesia et al. $[28,29]$ - was obtained to provide more precise information regarding neural conduction in the postretinal visual pathway. PERG and PVEP examinations were recorded with the RetiPort (Roland Consult) system, in accordance with the ISCEV PERG and PVEP standards [30-33].

At the beginning of the study, 10 patients with $\mathrm{AD}$ had the PERG and PVEP tests performed twice in two separate sessions for checking the reproducibility of measurements. Reproducible results were obtained. Variability was determined by calculating the coefficients 
Table 1 Early stages of Alzheimer's diseaseanalysis of the mean $\mathrm{CV}$ for parameters of PERG and PVEP tests $(n=10)$

$n$ number of eyes, $x$ arithmetic mean value, $S D$ standard deviation, $P$ significance level, $N S$ not significant, $I$ first examination, $I I$ second examination, $I T$ implicit time, $A$ amplitude, $L$ latency

\begin{tabular}{llrrrrc}
\hline Parameter & Measurement & \multicolumn{1}{l}{ Min } & \multicolumn{1}{c}{ Max } & \multicolumn{1}{c}{$\mathrm{x} \pm \mathrm{SD}$} & $\mathrm{CV}[\%]$ & $P$ value \\
\hline IT P50 [ms] & I & 47.00 & 56.00 & $51.30 \pm 3.09$ & 6.03 & NS \\
& II & 48.00 & 56.00 & $51.6 \pm 2.32$ & 4.49 & \\
A P50 $[\mu \mathrm{V}]$ & I & 2.63 & 3.90 & $3.61 \pm 0.36$ & 9.99 & NS \\
& II & 2.91 & 4.39 & $3.84 \pm 0.38$ & 9.96 & \\
A N95 $[\mu \mathrm{V}]$ & I & 3.82 & 5.42 & $4.29 \pm 0.44$ & 9.73 & NS \\
& II & 3.58 & 5.18 & $4.28 \pm 0.39$ & 9.03 & \\
L P100 [ms] & I & 106.00 & 120.00 & $111.0 \pm 4.81$ & 4.33 & NS \\
& II & 107.00 & 119.00 & $110.0 \pm 4.12$ & 3.72 & \\
L P100 [ms] & I & 105.00 & 129.00 & $122.00 \pm 7.59$ & 6.22 & NS \\
& II & 107.00 & 128.00 & $121.00 \pm 7.20$ & 5.91 & \\
\hline
\end{tabular}

Analysis of PERG parameters: amplitude and time of the P50- and N95-waves with manual correction to the automatic cursor placement were analyzed.

\section{PVEP test}

Preparation of the patient: pupils were undilated, appropriate refractive error correction in relation to the eye-screen distance, monocular stimulation, monitoring with the TV camera (to stop the stimulation when frequent blinking or fixation loss) was used.

Parameters of the pattern stimulation were as follows: $21^{\prime \prime}$ CRT monitor with a frame rate: $75 \mathrm{fps}$ was used, a black and white reversing checkerboard was presented to the patient with a check size: $1^{\circ} 4^{\prime}$ and $16^{\prime}$, luminance for the white elements: $120 \mathrm{~cd} / \mathrm{m}^{2}$ (mean luminance $55 \mathrm{~cd} / \mathrm{m}^{2}$ ), contrast: $97 \%$, temporal frequency: $2 \mathrm{rev} / \mathrm{s}(1 \mathrm{~Hz})$, and central fixation was carried out.

Electrodes: active-gold disk electrode placed on the scalp over the visual cortex at $\mathrm{Oz}$ with reference-gold disk electrode placed at Fz; groundgold disk electrode placed on the forehead at Fpz. The electrodes were placed relative to bone landmarks according to the international 10/20 system [34].

Parameters of the recording system were as follows: filters: 1-100 Hz, switched off notch filters, sweep time: $300 \mathrm{~ms}$, artifact reject threshold: $50 \mu \mathrm{V}$, averaging: 100 sweeps. Two consecutive waveforms were recorded, off-line averaged and then analyzed.

Analysis of PVEP parameters: amplitude and time of the P100-wave with manual correction to the automatic cursor placement were analyzed. Furthermore, in order to evaluate the bioelectrical function 
of macular vs more peripheral regions of the retina, differences between amplitudes of P100-wave in patients with the early stages of $\mathrm{AD}$ and control subjects after simulation with the small $\left(16^{\prime}\right)$ and large $\left(1^{\circ} 4^{\prime}\right)$ check stimuli were measured. The same comparisons were made between latencies of the P100-wave.

Retinocortical times (RCTs) were also compared, that is the difference between latency of P100-wave ( $16^{\prime}$ checks-RCT 1 and $1^{\circ} 4^{\prime}$ checks-RCT 2$)$ and implicit time of the P50-wave, following the methods described by Celesia et al. [28, 29].

Values of all parameters of patients with AD were compared with the values for the control group consisting of 30 eyes (always left) of 30 healthy individuals matched for age, sex, and refractive errors with $\mathrm{AD}$ patients.

The research was conducted in accordance with the principles of the Declaration of Helsinki, informed consent was obtained, and the protocol was approved by the local Independent Ethics Committee.

The Shapiro-Wilk test was used to evaluate compatibility with normal distribution of analyzed electrophysiological parameters. The PERG and PVEP parameters in eyes of patients with AD and eyes of the control group were compared in the following way: (1) for normally distributed data, the arithmetic mean and standard deviation was applied, and Student t-test was used (2) for abnormally distributed data, minimum-maximum value and median was used and evaluated with the MannWhitney $U$ test. The results of PERG and PVEP tests were considered normal when they included between mean and \pm two standard deviations $(\mathrm{x} \pm 2 \mathrm{SD})$ for normally distributed data or 2.5 and 97.5 percentiles for abnormally distributed data. The significance level of PERG and PVEP parameters was $<0.05$. For statistical calculations, the number of eyes tested was used, rather than the number of subjects.

\section{Results}

In the group of patients with AD, 33.0\% (10/30) had visual problems in the form of difficulty with reading, writing, or undefined visual disturbances, although their optimal visual acuity for near vision was J1.0 (Jaeger charts).

The statistical analyses of PERG and PVEP results are shown in Tables 2, 3, 4, 5, 6, 7. In the eyes of patients with AD, PERG test revealed statistically significant implicit time increase in the P50-wave $(P<0.03)$ and reduced P50- $(P<0.0001)$ and N95-wave $(P<0.0001)$ amplitudes in comparison with normal subjects (Table 2). Analysis of individual results of PERG parameters revealed abnormalities in $20.0 \%(6 / 30)$, $50 \%(15 / 30)$, and $56.7 \%(17 / 30)$ of the eyes, respectively. In the eyes of patients with AD in the PVEP test $\left(1^{\circ} 4^{\prime}\right.$ and $\left.16^{\prime}\right)$, a statistically significant increase in

Table 2 Early stages of Alzheimer's disease_-analysis of the mean amplitude and mean implicit time in PERG test in comparison with normal subjects

\begin{tabular}{|c|c|c|c|c|c|c|c|c|c|}
\hline & \multicolumn{8}{|c|}{ Amplitude $[\mu \mathrm{V}]$} & \multirow[t]{3}{*}{$P$ value } \\
\hline & \multicolumn{4}{|l|}{$\mathrm{AD}$} & \multicolumn{4}{|l|}{$\mathrm{C}$} & \\
\hline & Min & $\operatorname{Max}$ & $\mathrm{x} \pm \mathrm{SD}$ & Med & Min & Max & $\mathrm{x} \pm \mathrm{SD}$ & Med & \\
\hline P50 & 0.8 & 5.7 & $3.1 \pm 1.4$ & 2.9 & 2.2 & 8.2 & $4.9 \pm 1.4$ & 4.8 & $<0.0001^{*}$ \\
\hline N95 & 1.6 & 8.8 & $4.4 \pm 1.8$ & 4.0 & 3.8 & 11.9 & $7.1 \pm 2.2$ & 6.5 & $<0.0001 * *$ \\
\hline \multirow[t]{4}{*}{ N95/P50 ratio } & 0.6 & 2.8 & $1.5 \pm 0.4$ & 1.5 & 0.8 & 2.0 & $1.5 \pm 0.2$ & 1.5 & NS \\
\hline & \multicolumn{8}{|c|}{ Implicit time [ms] } & $P$ value \\
\hline & \multicolumn{4}{|l|}{$\mathrm{AD}$} & \multicolumn{4}{|l|}{$\mathrm{C}$} & \\
\hline & Min & $\operatorname{Max}$ & $\mathrm{x} \pm \mathrm{SD}$ & Med & Min & $\operatorname{Max}$ & $\mathrm{x} \pm \mathrm{SD}$ & Med & \\
\hline P50 & 43.0 & 61.0 & $51.8 \pm 4.1$ & 52.5 & 46.0 & 54.0 & $49.9 \pm 2.4$ & 49.5 & $<0.03 * *$ \\
\hline
\end{tabular}

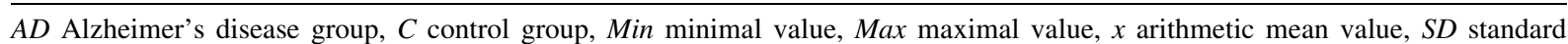
deviation, Med median, $P$ significance level, NS not significant; * normal distribution, ** not normal distribution 
Table 3 Early stages of Alzheimer's disease - analysis of the mean amplitude and mean latency of P100 in PVEP test $\left(1^{\circ} 4^{\prime}\right)$ in comparison with normal subjects

\begin{tabular}{|c|c|c|c|c|c|c|c|c|c|}
\hline & \multicolumn{8}{|c|}{ Amplitude $[\mu \mathrm{V}]$} & \multirow[t]{3}{*}{$P$ value } \\
\hline & \multicolumn{4}{|l|}{$\mathrm{AD}$} & \multicolumn{4}{|l|}{$\mathrm{C}$} & \\
\hline & Min & $\operatorname{Max}$ & $\mathrm{x} \pm \mathrm{SD}$ & Med & Min & $\operatorname{Max}$ & $\mathrm{x} \pm \mathrm{SD}$ & Med & \\
\hline \multirow[t]{4}{*}{ P100 } & 0.8 & 3.5 & $1.9 \pm 0.7$ & 2.0 & 0.8 & 6.4 & $2.2 \pm 1.4$ & 1.8 & NS \\
\hline & \multicolumn{8}{|c|}{ Latency [ms] } & $P$ value \\
\hline & \multicolumn{4}{|l|}{$\mathrm{AD}$} & \multicolumn{4}{|l|}{$\mathrm{C}$} & \\
\hline & Min & $\operatorname{Max}$ & $\mathrm{x} \pm \mathrm{SD}$ & Med & Min & Max & $\mathrm{x} \pm \mathrm{SD}$ & Med & \\
\hline P100 & 100.0 & 129.0 & $113.9 \pm 7.6$ & 110.5 & 92.0 & 116.0 & $105.0 \pm 5.6$ & 103.5 & $<0.0001 * *$ \\
\hline
\end{tabular}

$A D$ Alzheimer's disease group, $C$ control group, Min minimal value, Max maximal value, $x$ arithmetic mean value, $S D$ standard deviation, Med median, $P$ significance level, $N S$ not significant, ** not normal distribution

Table 4 Early stages of Alzheimer's disease-analysis of the mean amplitude and mean latency of P100 in PVEP test (16') in comparison with normal subjects

\begin{tabular}{|c|c|c|c|c|c|c|c|c|c|}
\hline & \multicolumn{8}{|c|}{ Amplitude $[\mu \mathrm{V}]$} & \multirow[t]{3}{*}{$P$ value } \\
\hline & \multicolumn{4}{|l|}{$\mathrm{AD}$} & \multicolumn{4}{|l|}{$\mathrm{C}$} & \\
\hline & Min & $\operatorname{Max}$ & $\mathrm{x} \pm \mathrm{SD}$ & Med & Min & Max & $\mathrm{x} \pm \mathrm{SD}$ & Med & \\
\hline \multirow[t]{4}{*}{ P100 } & 0.9 & 6.9 & $2.5 \pm 1.4$ & 2.1 & 0.6 & 8.7 & $2.5 \pm 1.6$ & 2.0 & NS \\
\hline & \multicolumn{8}{|c|}{ Latency [ms] } & $P$ value \\
\hline & \multicolumn{4}{|l|}{$\mathrm{AD}$} & \multicolumn{4}{|l|}{$\mathrm{C}$} & \\
\hline & Min & Max & $\mathrm{x} \pm \mathrm{SD}$ & Med & Min & Max & $\mathrm{x} \pm \mathrm{SD}$ & Med & \\
\hline $\mathrm{P} 100$ & 105.0 & 139.0 & $123.0 \pm 7.6$ & 126.0 & 95.0 & 124.0 & $114.1 \pm 7.1$ & 115.5 & $<0.0001 * *$ \\
\hline
\end{tabular}

$A D$ Alzheimer's disease group, $C$ control group, Min minimal value, Max maximal value, $x$ arithmetic mean value, $S D$ standard deviation, $M e d$ median, $P$ significance level, $N S$ not significant, ** not normal distribution

latency of the P100-wave $(P<0.0001)$ was observed (Tables 3, 4). Analysis of individual results in PVEP parameters revealed abnormalities in $43.3 \%$ (13/30) and $56.7 \%(17 / 30)$ of the $\mathrm{AD}$ eyes, respectively.

The results of comparisons of the difference between mean amplitude/mean latency of the P100wave in patients with the early stages of $\mathrm{AD}$ and in control individuals after stimulations of the small $\left(16^{\prime}\right)$ and large $\left(1^{\circ} 4^{\prime}\right)$ checks are shown in Table 5. Comparison of the P100-wave showed no statistically significant differences for the amplitudes or for the latencies.

In eyes of patients with $\mathrm{AD}$, significant prolonged RCT $(P<0.0001)$ was observed in comparison with controls (Tables 6, 7). Analysis of individual results revealed abnormalities for RCT1 in 10.0\% (3/30) and in RCT2 in $26.7 \%(8 / 30)$ of the AD eyes.
Table 5 Difference between mean amplitude/latency of the $\mathrm{P} 100$-wave in patients with the early stages of AD and mean amplitude/latency of the P100-wave in normal subjects after stimulation with the small $\left(16^{\prime}\right)$ and large $\left(1^{\circ} 4^{\prime}\right)$ check stimuli

\begin{tabular}{lllrll}
\hline & \multicolumn{3}{l}{ Amplitude $[\mu \mathrm{V}]$} & $P$ value \\
\cline { 2 - 5 } & Min & Max & $\mathrm{x} \pm \mathrm{SD}$ & $\mathrm{Med}$ & \\
\hline P100 $\left(1^{\circ} 4^{\prime}\right)$ & -5.4 & 2.3 & $-0.3 \pm 1.7$ & -0.2 & NS \\
P100 $\left(16^{\prime}\right)$ & -7.1 & 5.7 & $0.0 \pm 2.2$ & -0.2 & \\
\hline & Latency $[\mathrm{ms}]$ & & & $P$ value \\
\cline { 2 - 5 } & Min & Max & $\mathrm{x} \pm \mathrm{SD}$ & Med & \\
\hline P100 $\left(1^{\circ} 4^{\prime}\right)$ & -8.0 & 26.0 & $7.0 \pm 7.5$ & 7.0 & \multirow{2}{*}{ NS } \\
P100 (16 $)$ & -18.0 & 28.0 & $8.0 \pm 9.8$ & 7.5 & \\
\hline
\end{tabular}

Min minimal value, Max maximal value, $x$ arithmetic mean value, $S D$ standard deviation, Med median, $P$ significance level, NS not significant 
Table 6 Early stages of Alzheimer's disease-analysis of RCT 1 in comparison with normal subjects

\begin{tabular}{|c|c|c|c|c|c|c|c|c|}
\hline \multicolumn{8}{|c|}{ RCT 1 [LP100 (16 $\left.{ }^{\prime}\right)$ - LP50] } & \multirow[t]{3}{*}{$P$ value } \\
\hline \multicolumn{4}{|l|}{$\mathrm{AD}$} & \multicolumn{4}{|l|}{$\mathrm{C}$} & \\
\hline Min & Max & $\mathrm{x} \pm \mathrm{SD}$ & Med & Min & $\operatorname{Max}$ & $\mathrm{x} \pm \mathrm{SD}$ & Med & \\
\hline 58.0 & 89.0 & $72.2 \pm 6.4$ & 72.5 & 48.0 & 78.0 & $64.2 \pm 7.0$ & 65.0 & $<0.0001^{*}$ \\
\hline
\end{tabular}

$R C T$ retinocortical time, $A D$ Alzheimer's disease group, $C$ control group, Min minimal value, Max maximal value, $x$ arithmetic mean value, $S D$ standard deviation, $M e d$ median, $P$ significance level, * normal distribution

Table 7 Early stages of Alzheimer's disease-analysis of RCT 2 in comparison with normal subjects

\begin{tabular}{|c|c|c|c|c|c|c|c|c|}
\hline \multicolumn{8}{|c|}{ RCT 2 [LP100 $\left(1^{\circ} 4^{\prime}\right)$ - LP50] } & \multirow[t]{3}{*}{$P$ value } \\
\hline \multicolumn{4}{|l|}{$\mathrm{AD}$} & \multicolumn{4}{|l|}{$\mathrm{C}$} & \\
\hline Min & $\operatorname{Max}$ & $\mathrm{x} \pm \mathrm{SD}$ & Med & Min & Max & $\mathrm{x} \pm \mathrm{SD}$ & Med & \\
\hline 49.0 & 76.0 & $62.1 \pm 6.5$ & 60.5 & 42.0 & 70.0 & $55.1 \pm 5.9$ & 54.0 & $<0.0001^{*}$ \\
\hline
\end{tabular}

$R C T$ retinocortical time, $A D$ Alzheimer's disease group, $C$ control group, Min minimal value, Max maximal value, $x$ arithmetic mean value, $S D$ standard deviation, $M e d$ median, $P$ significance level, * normal distribution

Fig. 1 Early stages of Alzheimer's diseasefrequency of abnormalities in PERG and PVEP tests ( $A$ amplitude, $L$ latency, $R C T$ retinocortical time)

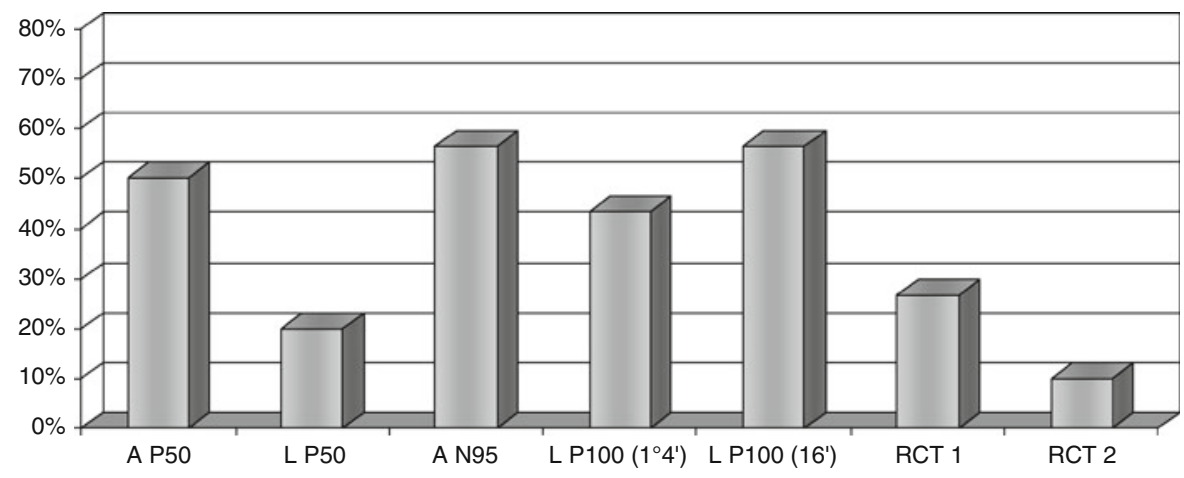

In Fig. 1, the frequency of abnormalities in PERG and PVEP tests in patients with the early stages of $\mathrm{AD}$ is shown.

Examples of abnormal PERG and PVEP recordings in patients with AD are presented in Figs. 2, 3, 4. In Fig. 5, scatter-plots of PERG (amplitudes of P50and N95-waves and implicit time of P50-wave) and PVEP (latencies of P100-wave) as a function of age are shown.

\section{Discussion}

The results of our study strongly suggest, for the first time, that in patients with the early stages of $\mathrm{AD}$, bioelectrical dysfunction of retinal ganglion cells and the optic nerve is present and this is registered by

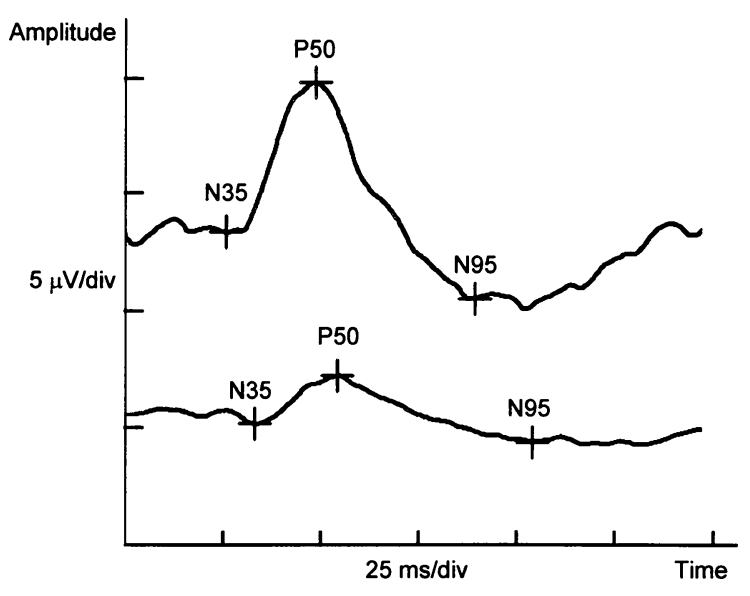

Fig. 2 PERG-P50-wave latency delay and reduced amplitudes of P50- and N95-wave in a patient with the early stage of Alzheimer's disease (below) in comparison with the normal control (above) 


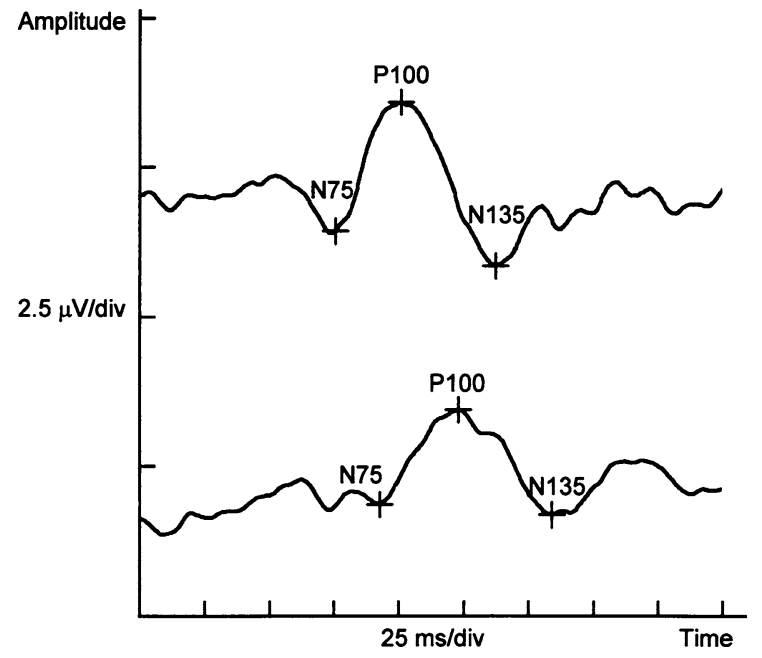

Fig. 3 PVEP $\left(1^{\circ} 4^{\prime}\right)-P 100$-wave latency delay in a patient with the early stage of Alzheimer's disease (below) in comparison with the normal control (above)

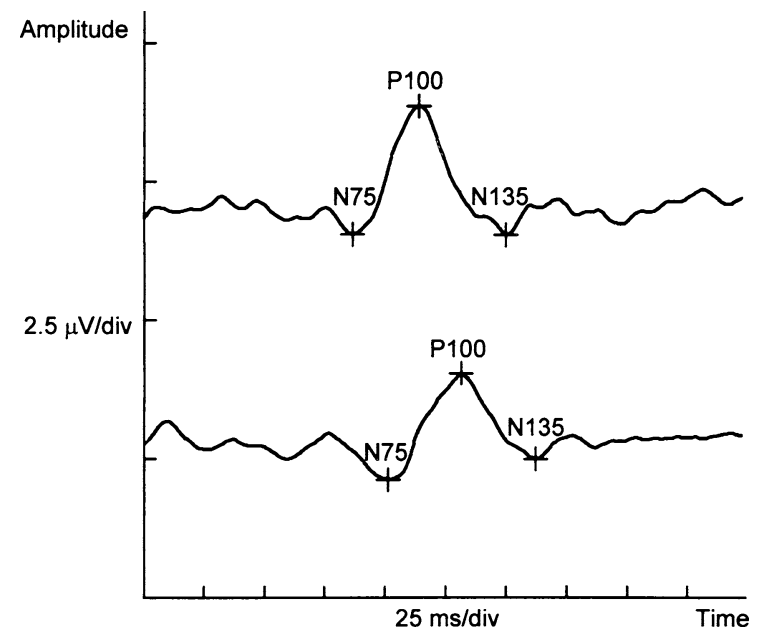

Fig. 4 PVEP $\left(16^{\prime}\right)$-P100-wave latency delay in a patient with the early stage of Alzheimer's disease (below) in comparison with the normal control (above)

PERG and PVEP tests. Previously, some researchers [15-21] also reported abnormalities in PERG and PVEP tests in patients with AD but they considered different stages of this disease, with the exception of one study in which reduced amplitude of P100 in PVEP examination in patients with the early stages of AD was detected [20]. Furthermore, PERG and PVEP tests were usually performed on small numbers of patients and in which between-group comparisons were made.
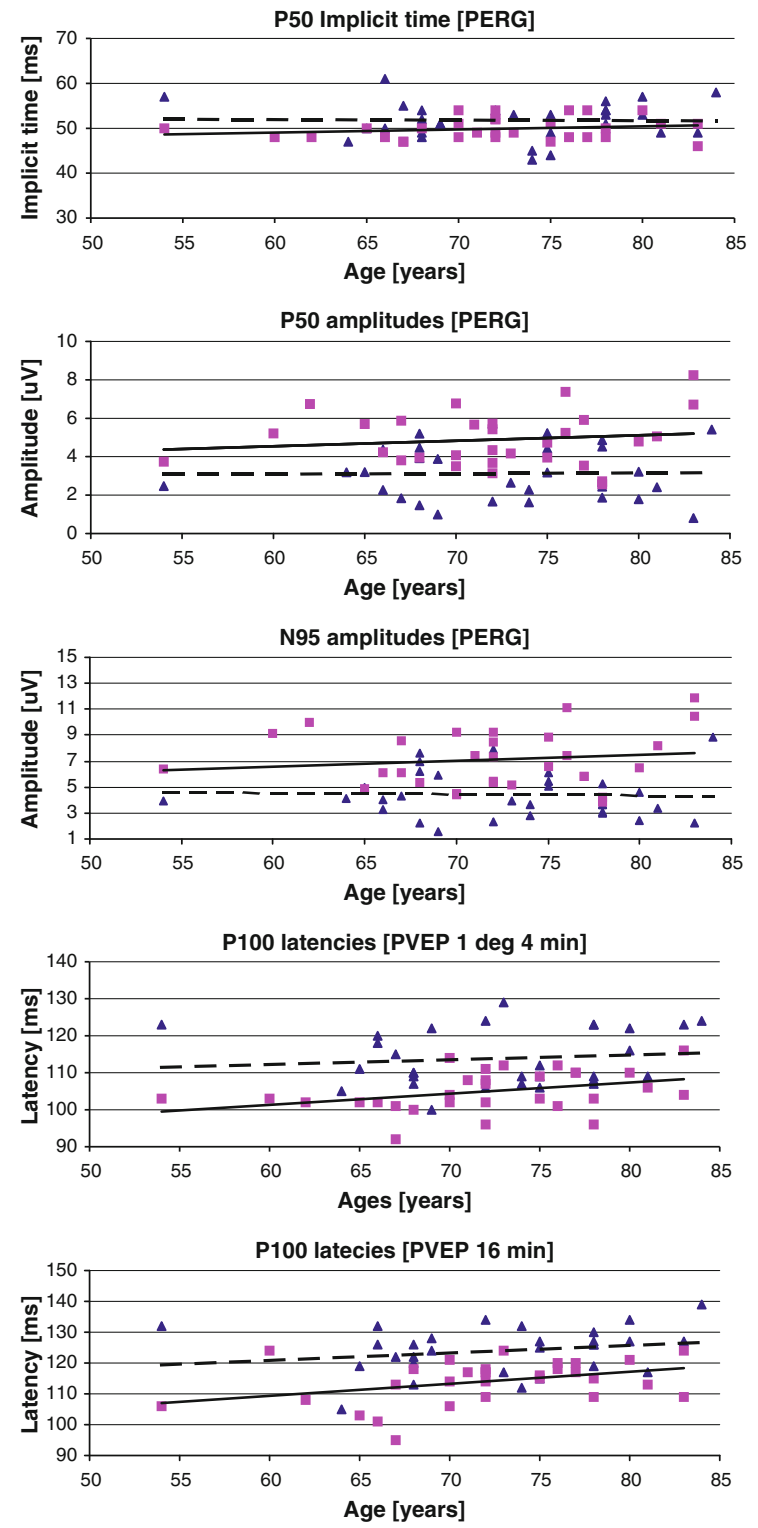

Fig. 5 Early stages of Alzheimer's disease-scatter-plot of PERG (amplitudes of P50- and N95-waves and implicit time of P50-wave) and PVEP (latencies of P100-wave) as a function of age (filled triangle Alzheimer's disease group, filled square control group, horizontal line linear regression for AD group, black rectangle linear regression for control group)

It is worthwhile to note that recording of PERG and PVEP tests in patients with AD is not easy because of the possible secondary effects of defocus or other behavioral problems. To minimize these problems, in our study, appropriate selection of patients was made. We performed electrophysiological tests only in early 
stages of $\mathrm{AD}$ when patients had minimal disturbances of cognitive function and their cooperation was very good. PERG and PVEP examinations were recorded by the first author of presented manuscript who was familiar with the PERG and PVEP procedures and understood possible difficulties with cooperation in patients with $\mathrm{AD}$.

In the present study, in patients with the early stages of $\mathrm{AD}$, we noticed statistically significant abnormalities in PERG and in PVEP examinations (PERG: implicit time increase in P50-wave $(P<0.04)$, reduced amplitudes of P50- and N95wave $(P<0.0001)$; PVEP (checkerboard: $1^{\circ} 4^{\prime}$ and $\left.16^{\prime}\right)$ : latency increase in $\mathrm{P} 100$-wave $(P<0.0001)$. We also found statistically prolonged RCT $(P<0.0001)$. What is worthwhile to note, amplitude reduction of N95-wave in PERG examination, and latency increase of P100-wave in PVEP $\left(16^{\prime}\right)$ examination was found in more than $50 \%$ of analyzed $\mathrm{AD}$ eyes (Fig. 1).

N95-wave provides a measure of ganglion cells function but approximately $70 \%$ of the P50-wave is also generated by the ganglion cells [35]. The remaining $30 \%$ may be generated more distally [36, 37]. Amplitude reduction and implicit time shortening of the P50-wave are indicators of ganglion cells/ optic nerve dysfunction. P50-wave implicit time increase is not a characteristic feature of optic nerve or ganglion cell disease [35, 37]—it may be seen in some maculopathies such as in macular edema [38].

In our group of patients with the early stages of $\mathrm{AD}$, the observed reduced amplitude of N95-wave confirms the dysfunction of ganglion cells, whereas reduced amplitude and implicit time increase in P50wave may be related to dysfunction, not only of the ganglion cells, but also of the outer layers of the retina in relation to the ganglion cells.

P-100 wave reflects the bioelectrical function of the optic nerve $[37,39]$. Latency increase in P100wave may be a subclinical feature of optic nerve dysfunction, and it may be detected without any pathological changes in routine ophthalmological examination [40]. The results obtained in patients with the early stages of AD showed increased latency of P100 and consistent with optic nerve dysfunction.

RCT may independently indicate neural conduction in the postretinal visual pathway [28, 29]. An example confirming this hypothesis is normal RCT but abnormal PERG and PVEP tests in patients with maculopathies. In this case, latency increase in PVEP test might be a consequence of abnormalities revealed in the PERG test.

In the group of patients with the early stages of $\mathrm{AD}$, latency increase in P50- and P100-waves and prolonged RCT without any clinical signs of maculopathies were observed. Therefore, results of our study suggest that abnormalities in PERG/PVEP tests and in RCT could be connected not only with impaired neural conduction in the visual pathway including the optic nerve but also with dysfunction of the inner retinal layers. Previously, prolonged RCT was observed in neuropathies in the course of some diseases, e.g., in multiple sclerosis [29] and glaucoma [41]. According to Lam [39], different sizes of the check stimulus in PVEP test stimulate different parts of the retina. The large check stimulus elicits more parafoveal response and small check stimulus elicits a mainly foveal response. We also investigated the difference in PVEP examination between stimulation in the foveal and parafoveal region in patients with the early stages of AD.

Comparative analysis between amplitudes and latencies (Tables 4,5$)$ after large $\left(1^{\circ} 4^{\prime}\right)$ and small $\left(16^{\prime}\right)$ checks stimulation showed no statistically significant differences. Lack of regional differentiation in PVEP responses between the foveal and parafoveal part of the retina shows that in the early stages of $\mathrm{AD}$, the optic nerve fibers can be evenly disturbed.

Most authors [2, 22] suggest that in patients with $\mathrm{AD}$, visual disturbances are caused by neuropathological changes in the visual cortex. The results obtained in the current study show that visual disturbances in $\mathrm{AD}$ may also be related to the retinal ganglion cells and optic nerve dysfunction.

The possible causes of visual abnormalities mentioned earlier may be due to beta-amyloid and amyloid precursor protein (APP) deposits in the retina and optic nerve as well as retinal neurotransmitter deficits, mainly acetylcholine [42-44].

Some researchers observed the cytotoxic influence of aggregated beta-amyloid on neurons that express neurotransmitters, including acetylcholine [45]. Berisha et al. [8] observed that patients with early AD showed a significant thinning of retinal nerve fiber layer (RNFL), as measured by OCT. This may be connected with beta-amyloid aggregation and neuronal degeneration in the retina.

Acetylcholine plays an important role in the process of vision because it is essential for the proper 
functioning of retinal cells. Acetylcholine receptors are distributed predominantly in the inner retinal layers and also, but in smaller densities, in the outer layers of the retina [14, 46]. The indicators of dysfunction to the ganglion cells and to the outer layers of the retina are changes observed in N95wave and in P50-waves of PERG examination, respectively.

Additional evidence suggesting that acetylcholine may play a role in observed abnormalities in patients with $\mathrm{AD}$ comes from a monkey study investigating the influence of acetylcholine level on PERG examination [47]. Administration of an acetylcholine precursor caused increased amplitudes in PERG test. In another studies, the effect of acetylcholine level was also explored on flash visual potentials (FVEP) recordings in healthy subjects [48, 49]. Administration of galanthamine - an inhibitor of the enzyme that breaks down acetylcholine-resulted in increased amplitudes [48] while the administration of the acetylcholine antagonist, scopolamine, caused reduction of P2-wave amplitude in FVEP test [49].

Thus, in patients with the early stages of $\mathrm{AD}$, the dysfunction of retinal ganglion cells and the optic nerve as measured by PERG and PVEP examinations may be associated with the beta-amyloid deposits and neurotransmitters deficits.

In the current study group, visual complaints were observed in $1 / 3(10 / 30)$ analyzed patients with the early stages of AD. Furthermore, the majority (7/10) had abnormalities in electrophysiological tests. In the remaining patients without visual symptoms, electrophysiological abnormalities are an indicator of conductive deterioration in visual pathway and can be a subclinical ocular feature of AD.

In the future, it would be worth to perform additional research in patients with the early stages of $\mathrm{AD}$ to include results of PERG responses to different check sizes (similar to the VEP recordings) and to correlate the data with OCT. In the present study in only a few patients in the early stages of AD, the OCT was performed, because the OCT equipment was available at the end of our research project. What is important, all these patients had normal OCT results, but abnormal PERG and PVEP examinations. Therefore, these examples suggest that dysfunction of the ganglion cells measured by electrophysiological tests precedes the structural changes in the ganglion cell layer. We believe that it might be true, because in other studies $[24,50]$, changes in OCT were observed in advanced but not in the early stages of AD.

The dysfunction of retinal ganglion cells and the optic nerve may, at least partially, explain the cause of visual disturbances reported by patients with the early stages of Alzheimer's disease and with apparently normal eyes.

This dysfunction might be a characteristic feature of $\mathrm{AD}$ and may be useful in the differential diagnosis. Further investigations in a larger group of patients with $\mathrm{AD}$ and also in patients with other types of dementia are necessary to confirm our suggestion.

Open Access This article is distributed under the terms of the Creative Commons Attribution Noncommercial License which permits any noncommercial use, distribution, and reproduction in any medium, provided the original author(s) and source are credited.

\section{References}

1. Lobo A, Launer LJ, Fratiglioni L, Andersen K, Di Carlo A, Breteler MM, Copeland JR, Dartigues JF, Jagger C, Martinez-Lage J, Soininen H, Hofman A (2000) Prevalence of dementia and major subtypes in Europe: a collaborative study of population-based cohorts. Neurologic diseases in the elderly research group. Neurology 54:4-9

2. Mendez MF, Mendez MA, Martin R, Smyth KA, Whitehouse PJ (1990) Complex visual disturbances in Alzheimer's disease. Neurology 40:439-443

3. Holoryd S, Sphepherd ML (2001) Alzheimer's disease: a review for the ophthalmologist. Surv Ophthalmol 45: 516-524

4. Sadun AA, Bassi CJ (1990) The visual system in Alzheimer's disease. Res Publ Assoc Res Nerv Ment Dis 67:331-347

5. Katz B, Rimmer S (1989) Ophthalmologic manifestations of Alzheimer's disease. Surv Ophthalmol 34:31-43

6. Pelak VS, Hall DA (2004) Neuro-ophthalmic manifestations of neurodegenerative disease. Ophthalmol Clin North Am 17:311-320

7. Fletcher WA (1994) Ophthalmological aspects of Alzheimer's disease. Curr Opin Ophthalmol 5:38-44

8. Berisha F, Feke GT, Trempe CL, McMeel JW, Schepens CL (2007) Retinal abnormalities in early Alzheimer's disease. Invest Ophthalmol Vis Sci 48:2285-2289

9. Hinton DR, Sadun AA, Blanks JC, Miller CA (1986) Optic-nerve degeneration in Alzheimer's disease. N Engl J Med 315:485-487

10. Danesh-Meyer HV, Birch H, Ku JY, Carroll S, Gamble G (2006) Reduction of optic nerve fibers in patients with Alzheimer disease identified by laser imaging. Neurology 67:1852-1854

11. Syed AB, Armstrong RA, Smith CU (2005) A quantitative analysis of optic nerve axons in elderly control subjects and patients with Alzheimer's disease. Folia Neuropathol 43:1-6 
12. Frederikse PH, Garland D, Zigler JS Jr, Piatigorsky J (1996) Oxidative stress increases production of beta-amyloid precursor protein and beta-amyloid (Abeta) in mammalian lenses, and Abeta has toxic effects on lens epithelial cells. J Biol Chem 271:10169-10174

13. Bruban J, Glotin AL, Dinet V, Chalour N, Sennlaub F, Jonet L, An N, Faussat AM, Mascarelli F (2009) Amyloidbeta(1-42) alters structure and function of retinal pigmented epithelial cells. Aging Cell 8:162-177

14. Townes-Anderson E, Vogt BA (1989) Distribution of muscarinic acetylcholine receptors on processes of isolated retinal cells. J Comp Neurol 290:369-383

15. Katz B, Rimmer S, Iragui V, Katzman R (1989) Abnormal pattern electroretinogram in Alzheimer's disease: evidence for retinal ganglion cell degeneration? Ann Neurol 26:221-225

16. Trick GL, Barris MC, Bickler-Bluth M (1989) Abnormal pattern electroretinogram in patients with senile dementia of the Alzheimer type. Ann Neurol 26:226-231

17. Parisi V, Restuccia R, Fattapposta F, Mina C, Bucci MG, Pierelli F (2001) Morphological and functional retinal impairment in Alzheimer's disease patients. Clin Neurophysiol 112:1860-1867

18. Partanen J, Hartikainen P, Könönen M, Jousmäki V, Soinien H, Riekkinen P (1994) Prolonged latencies of pattern reversal visual evoked early potentials in Alzheimer disease. Alzheimer Dis Assoc Disord 8:250-258

19. Pollock VE, Schneider LS, Chui HC, Henderson V, Zemansky M, Sloane RB (1989) Visual evoked potentials in dementia: a meta-analysis and empirical study of Alzheimer's disease patients. Biol Psychiatry 25:1003-1013

20. Grayson AS, Weiler EM, Sandman DE (1995) Visual evoked potentials in early Alzheimer's dementia: an exploratory study. J Gen Psychol 122:113-129

21. Kergoat H, Kergoat MJ, Justino L, Chertkow H, Robillard A, Bergman H (2002) Visual retinocortical function in dementia of the Alzheimer's type. Gerontology 48:197-203

22. Rizzo JF 3rd, Cronin-Golomb A, Growdon JH, Corkin S, Rosen TJ, Sandberg MA, Chiappa KH, Lessell S (1992) Retinocalcarine function in Alzheimer's disease. A clinical and electrophysiological study. Arch Neurol 49:93-101

23. Strenn K, Dal-Bianco P, Weghaupt H, Koch G, Vass C, Gottlob I (1991) Pattern electroretinogram and luminance electroretinogram in Alzheimer's disease. J Neural Transm Suppl 33:73-80

24. Iseri P, Altinaş Ö, Tokay T, Yüskel N (2006) Relationship between cognitive impairment and retinal morphological and visual functional abnormalities in Alzheimer disease. $\mathbf{J}$ Neuro-Ophthalmol 26:18-24

25. Philpot MP, Amin D, Levy R (1990) Visual evoked potentials in Alzheimer's disease: correlation with age and severity. Electroencephalogr Clin Neurophysiol 77:323-329

26. McKhann G, Drachman D, Folstein M, Katzman R, Price D, Stadlan EM (1984) Clinical Diagnosis of Alzheimer's disease: report of the NINCDS-ADRDA work group under the auspices of the department of health and human services task force on Alzheimer's disease. Neurology 34:939-944

27. Folstein MF, Folstein SE, McHugh PR (1975) Mini-mental state. A practical method for grading the cognitive state of patients for the clinician. J Psychiatr Res 12:189-198
28. Celesia GG, Kaufman D (1985) Pattern ERGs and visual evoked potentials in maculopathies and optic nerve diseases. Invest Ophthalmol Vis Sci 26:726-735

29. Celesia GG, Kaufman D, Cone SB (1986) Simultaneous recording of pattern electroretinography and visual evoked potentials in multiple sclerosis. A method to separate demyelination from axonal damage to the optic nerve. Arch Neurol 43:1247-1252

30. Bach M, Hawlina M, Holder GE, Marmor MF, Meigen T, Vaegan, Miyake Y (2000) Standard for pattern electroretinography. Doc Ophthalmol 101:11-18

31. Holder GE, Brigell MG, Hawlina M, Meigen T, Vaegan, Bach M (2007) ISCEV standard for clinical pattern electroretinography-2007 update. Doc Ophthalmol 114: 111-116

32. Odom JV, Bach M, Barber C, Brigell M, Marmor MF, Tormene AP, Holder GE, Vaegan (2004) Visual evoked potentials standard (2004). Doc Ophthalmol 108:115-123

33. Odom JV, Bach M, Brigell M, Holder GH, McCulloch DL, Tormene AP, Vaegan (2010) ISCEV standard for clinical Visual Evoked Potentials Standard (2009 update). Doc Ophthalmol 120:111-119

34. American Clinical Neurophysiology Society (2006) Guideline 5: guidelines for standard electrode position nomenclature. J Clin Neurophysiol 23:107-110

35. Holder GH (2006) The pattern electroretinogram. In: Heckenlively JR, Arden GB (eds) Principles and practice of clinical electrophysiology of vision, 2nd edn. MIT Press, Cambridge, pp 341-351

36. Viswanathan S, Frishman LJ, Robson JG (2000) The uniform field and pattern ERG in macaques with experimental glaucoma: removal of spiking activity. Invest Ophthalmol Vis Sci 41:2797-2810

37. Holder GH (2006) Localizing lesions in the visual system. In: Heckenlively JR, Arden GB (eds) Principles and practice of clinical electrophysiology of vision, 2nd edn. MIT Press, Cambridge, pp 505-517

38. Eckstein MB, Spalton DJ, Holder G (1993) Visual loss from central serous retinopathy in systemic lupus erythematosus. Br J Ophthalmol 77:607-609

39. Lam BL (2005) Visual evoked potential. In: Lam BL (ed) Electrophysiology of vision. Clinical testing and applications, 1 st edn. Taylor\&Francis Group, Boca Raton, pp 123-135

40. Bodis-Wollner I, Antal A (2006) Optic nerve and central nervous dysfunctions: Parkinson's disease and multiple sclerosis. In: Heckenlively JR, Arden GB (eds) Principles and practice of clinical electrophysiology of vision, 2nd edn. MIT Press, Cambridge, pp 341-351

41. Parisi V, Pernini C, Guinetti C, Neuschuler R, Bucci MG (1997) Electrophysiological assessment of visual pathways in glaucoma. Eur J Ophthalmol 7:229-235

42. Löffler KU, Edward DP, Tso MO (1995) Immunoreactivity against tau, amyloid precursor protein, and beta-amyloid in the human retina. Invest Ophthalmol Vis Sci 36:24-31

43. Liu B, Rasool S, Yang Z, Glabe CG, Schreiber SS, Ge J, Tan Z (2009) Amyloid-peptide vaccinations reduce $\{$ beta $\}$ amyloid plaques but exacerbate vascular deposition and inflammation in the retina of Alzheimer's transgenic mice. Am J Pathol 175:2099-2110 
44. Melo JB, Agostinho P, Oliveira CR (2002) Amyloid betapeptide $25-35$ reduces $[3 \mathrm{H}]$ acetylcholine release in retinal neurons. Involvement of metabolic dysfunction. Amyloid 9:221-228

45. Aruoma OI, Jen SS, Watts HR, George J, Gentleman SM, Anderson PJ, Jen LS (2009) Acute and chronic effects of intravitreally injected beta-amyloid on the neurotransmitter system in the retina. Toxicology 256:92-100

46. Dimitrieva NA, Christianne ES, Kent TK (2007) Expression of alpha 7 nicotinic acetylcholine receptors by bipolar, amacrine, and ganglion cells of the rabbit retina. J Histochem Cytochem 55:461-476

47. Antal A, Kéri S, Bodis-Wollner I (1999) L-alpha-glycerylphosphorylcholine enhances the amplitude of the pattern electroretinogram in rhesus monkeys. A pilot study. Neurobiology 7:407-412
48. Holl G, Straschill M, Thomsen T, Fischer JP, Kewitz H (1992) Effect of the cholinesterase inhibiting substance galanthamine on human EEG and visual evoked potentials. Electroencephalogr Clin Neurophysiol 82:445-452

49. Sannita WG, Balestra V, DiBon G, Marotta V, Rosadini G (1993) Human flash-VEP and quantitative EEG are independently affected by acute scopolamine. Electroencephalogr Clin Neurophysiol 86:275-282

50. Kergoat H, Kergoat KJ, Justino L, Chertkow H, Robillard A, Bergman H (2001) An evaluation of the retinal nerve fibre layer thickness by scanning laser polarimetry in individuals with dementia of the Alzheimer type. Acta Ophthalmol Scand 79:187-191 